\title{
Harmonic Scalpel for Internal Mammary Artery Harvest
}

\author{
Shi-Min Yuan \\ Department of Cardiothoracic Surgery, The First Hospital of Putian, Teaching Hospital, Fujian Medical University, Putian, Fujian Province, \\ People's Republic of China
}

\begin{abstract}
Internal mammary artery (IMA) harvest by using a harmonic scalpel for coronary artery bypass grafting (CABG) have not been sufficiently evaluated. This review aimed to assess the outcomes of IMA harvest by a harmonic scalpel and to compare by conventional electrocautery. The study materials were based on literature retrieval. In total Eight articles describing IMA harvest by a harmonic scalpel for 1,893 patients, and pateints with IMA harvest by electrocautery were taken as controls. IMA harvest by a harmonic scalpel was associated with less thermal injury with potentially better preservation of the endothelial cells, satisfactory intraoperative IMA flow, and promising postoperative IMA patency. Apart from the harvesting merits, the harmonic scalpel had many other advantages in terms of clinical outcomes, such as decreased postoperative mortality and morbidity rates. Nevertheless, IMA harvesting by using a harmonic scalpel is associated with longer harvest time, prolonged operative time, and increased hospitalisation expenses. Therefore, they could be used in selected and non-emergent patients for CABG.
\end{abstract}

Key Words: Coronary artery bypass grafting, Internal mammary artery, Surgical instruments.

How to cite this article: Yuan SM. Harmonic Scalpel for Internal Mammary Artery Harvest. J Coll Physicians Surg Pak 2020; 30(05):516-518. DOI: https://doi.org/10.29271/jcpsp.2020.05.516.

\section{INTRODUCTION}

The application of electrocautery in surgical operation can be dated back to 1929, when Heckel reported his experiences of eyelid epithelioma removal. ${ }^{1}$ Electrocautery is a technique with potential advantages of removing large quantities of tumor safely, painlessly, and without measurable blood loss. ${ }^{2}$ Vascular graft harvest by electrocautery is fast by dissecting the pedicle away from the chest wall, and the use of electrocautery facilitates the skeletonisation of the internal mammary artery (IMA) takedown. ${ }^{3}$ However, IMA harvest by using electrocautery may cause arterial spasms, and thus the scissors and silver clips are often used instead of gentle maneuvers for preventing from the potential adverse events. ${ }^{3}$ The advent of the harmonic scalpel provides with an alternative device for IMA harvest with more advantages over the conventional cautery.

The harmonic scalpel was firstly applied for IMA harvest in CABG in $1994 .^{4}$ The harmonic scalpel ensures simultaneous cut and cauterisation of the dissected tissues, thereby resulting in advanced hemostasis, more securely sealing of the larger vessels, and less tissue damage. ${ }^{5}$ However, the outcomes of the patients with IMA harvest by a harmonic scalpel for CABG have not been comprehensively elucidated. This article aims to assess the effects of IMA harvest by a harmonic scalpel and to compare with those by conventional electrocautery.

Correspondence to: Shi-Min Yuan, Department of Cardiothoracic Surgery, The First Hospital of Putian, Teaching Hospital, Fujian Medical University, 389 Longdejing Street, Chengxiang District, Putian 351100, Fujian Province, People's Republic of China.

E-mail: shiminyuan@126.com

Received: February 21, 2020; Revised: May 01, 2020;

Accepted: May 01, 2020

DOI: https://doi.org/10.29271/jcpsp.2020.05.516

\section{METHODOLOGY}

The Preferred Reporting Items for Systematic Reviews and Meta-analyses (PRISMA) statement guidelines were followed in this meta-analysis. Publications were systematically searched in the PubMed, Highwire Press, and the Cochrane Library databases from January 1998 to December 2018. The MeSH terms and keywords identifying articles included "internal mammary artery", "harmonic scalpel", "harvest technique", "coronary artery bypass grafting", "off-pump coronary artery bypass", "minimally invasive direct coronary artery bypass", and "electrocautery". The screening of the bibliographic references helped in completing the literature retrieval. Twenty-six articles were found related to the topic and keywords in the literature search; and eight articles, which met the inclusion criteria during preliminary assessment, were included in this review. The exclusion criteria were: lack of patient information ( $n=12)$, only electrocautery as a harvest device $(n=3)$, and radial artery harvest by using a harmonic scalpel $(n=3)$.

The data independently extracted from each study were the study population, demographics, surgical procedures, harvest time, intraoperative IMA graft flow, injury to IMAs, IMA patency rate, and patients' outcomes.

Measurement data were expressed in mean \pm standard deviation, and compared by independent sample t-test. Categorical variables were expressed as frequency along with percentages, and were compared by Fisher exact test. IBM SPSS statistics software version 22.0 was used for performing the statistical analyses. $\mathrm{P}<0.05$ was considered statistically significant.

\section{RESULTS}

Eight articles were evaluated for this study. ${ }^{6-13}$ There were 1,893 patients in these studies, in whom IMA grafts were harvested by using a harmonic scalpel. The gender of 47 (2.5\%) patients was 
unspecified. Of the remaining 1,846 (97.5\%) patients, 1,386 (75.1\%) were male and $460(24.9 \%)$ were female patients. The CABG techniques performed in these patients were conventional CABG procedures $(n=1,461,77.2 \%)$ and off-pump coronary artery bypass $(n=432,22.8 \%)$.

In five (62.5\%) reports, one or two control groups were set-up, including 430 patients undergoing CABG. Electrocautery IMA harvest was as control in all five studies. ${ }^{7,10-13}$ Argon beam coagulator IMA harvest was the control in one of these reports. ${ }^{7}$ In the control groups, gender of 12 patients was not specified. In the remaining 416 patients, 314 (75.1\%) patients were male and 104 (24.9\%) were female patients. There was no difference in patient age between the harmonic scalpel and the control groups (63.4 \pm 3.1 vs. $63.6 \pm 3.6, p=0.938$ ).

In four (50\%) reports, ${ }^{7,8,10,12}$ the number of IMAs was reported; as a result, 2,331 IMAs were harvested in 1,635 patients (median, 1 IMA per patient) in the harmonic scalpel group, and 436 IMAs were harvested in 375 patients (median, 1 IMA per patient) in the control group. In two reports, ${ }^{8,10}$ the sides of 1,859 IMAs harvested by a harmonic scalpel were reported for 1,225 patients: 1,038 (55.8\%) were left IMAs, 700 (37.7\%) were right IMAs, and 121 $(6.5 \%)$ were bilateral IMAs $\left(\chi^{2}=1041.2, p<0.001\right)$. The harvest time was similar by both harmonic and electrocautery harvest (Tablel).

Table I. A comparison of the outcomes of harmonic scalpel versus electrocautery.

\begin{tabular}{|l|l|l|l|}
\hline Variable & Harmonic scalpel & Electrocautery & p-value \\
\hline Harvest time (min) & $16.8 \pm 5.7$ & $20.1 \pm 10.9$ & 0.560 \\
\hline $\begin{array}{l}\text { Postoperative graft } \\
\text { flows (mL/min) }\end{array}$ & $34.9 \pm 1.9$ & $25.1 \pm 4.3$ & 0.014 \\
\hline Hemostatic clip use & $0.6 \pm 0.5$ & $18.5 \pm 2.7$ & $<0.001$ \\
\hline IMA: Internal mammary artery. & \\
\hline
\end{tabular}

Table II. Advantages and disadvantages of the harmonic scalpel. ${ }^{16}$

\begin{tabular}{|l|}
\hline Advantages and disadvantages \\
\hline No muscle stimulation \\
No arterial spasm \\
Minimal smoke \\
Less heat creation \\
Minimal thermal injury \\
Superb coagulation \\
Fast healing \\
Less instrument transfer \\
Less hemostatic clip demand \\
Difficult maneuvre \\
Prolonged harvest time \\
Safty and efficacy in pacemaker patients \\
\hline
\end{tabular}

Fewer hemostatic clips were used when IMA was harvested by using a harmonic scalpel in comparison to conventional electrocautery (Table I). In two (25\%) reports, ${ }^{6,9}$ the postoperative IMA graft patency was detected angiographically in 358 IMA grafts with a patency rate of $99.6-100 \%$. The patency rate of the right IMAgrafts was a little bit higher than that of the left. The postoperative IMA flow was higher in harmonic scalpel group patients than in electrocautery group patients (Table I). The rate of conversion to sternotomy to complete IMA harvest did not differ between the two groups[4.7\%(77/1635) and $\left.2.7 \%(10 / 375)\left(\chi^{2}=3.1, p=0.091\right)\right]$.

\section{DISCUSSION}

The IMAs are a preferred graft material for CABG due to their promising long-term patency rates. ${ }^{14}$ The electrocautery is a conventional device for a fast IMA harvest. ${ }^{15}$ However, it was found that IMA harvest by using electrocautery was associated with graft endothelial damage and occasional mural thrombus formation. ${ }^{15}$ This was probably caused by the surgical techniques used and/orthe thermal damage generated by the electrocautery. ${ }^{4}$

Concerning the drawbacks of the electrocautery, some alternative devices, such as the radiofrequency-knife, argon-beam coagulator, and harmonic scalpel, were gradually introduced into clinical practice aiming at lessoning the IMA damage during harvesting and enhancing the long-term patency of the IMA grafts. A comparative study between the electrocautery and radiofrequency-knife showed that the electrocautery carried 2.8 times higher thermal damage of the endothelium of the IMAs than radiofrequency-knife, and the damage tended to be aggregated in proportion to patients' age. ${ }^{16}$ Brose et al. compared three devices for IMA harvest (harmonic scalpel, argon beam coagulator, and electrocautery), and observed that the harmonic scalpel required fewer hemostatic clips, but longer harvest time than the other two groups. ${ }^{17}$ This viewpoint was supported by many other authors. However, Balcı et al. reported an opposite result as they took shorter time for IMA harvest by using a harmonic scalpel. ${ }^{6}$

As the harmonic scalpel functions for both cutting and coagulating the vessels, these vessels could be sealed with a denatured protein coagulum, thereby eliminating the hemostatic clip use. ${ }^{17}$ Harmonic scalpel use was thus associated with less hemastatic clip requirement; ${ }^{7}$ and even in some patients, no hemostatic clip was used at all. ${ }^{6}$

Kiaii et al. observed IMA injury during IMA harvest, ${ }^{18}$ whereas Ohtsuka et al. and Orejola et al. proposed that there was no thermic damage of the IMA when a harmonic scalpel was used for graft harvest. ${ }^{4,12}$ Brose et al. also reported that IMA harvest did not cause endothelial cell loss of the IMAs by any of the three devices they used for IMA harvest. ${ }^{17}$ Although some pathological changes, such as parietal thrombus, periadventitial bleeding, ruptured intima, and arterial wall edema, occurred individually, no difference was noted between the three devices. These results indicated that the harmonic scalpel was a safe tool for IMA harvest, at least compatible to the alternative harvest devices.

For evaluation of harmonic scalpel-harvested IMA, IMA flow detections by intraoperative echocardiography and by postoperative angiography are popularly utilised as a valuable parameter. Satisfactory intraoperative IMA flow after harmonic scalpel harvest has been described, ${ }^{4}$ but the quantitative results were heterogeneous, as it was reported to be in a very wide range of 14-126 $\mathrm{mL} / \mathrm{min} .{ }^{17}$ Higami et al. reported a very high average value of IMA flow of $122.2 \pm 44.8 \mathrm{~mL} / \mathrm{min}$ of the left IMA and a flow of 137.6 $\pm 51.7 \mathrm{~mL} / \mathrm{min}$ of the right IMA, ${ }^{9}$ but they did not compare the results with those of the electrocautery. In general, the mean IMA flow of the harmonic group patients was much higher than that of the electrocautery. The patency rate of the IMAs harvested by 
using a harmonic scalpel was promising as detected by postoperative angiography. Kieser et al. reported that the left IMA patency for patients with and without harmonic skeletonisation was $96.2 \%$ versus $100 \% .{ }^{19}$ Apart from the harvesting merits, the harmonic scalpel has many other advantages in terms of clinical outcomes, such as lower postoperative mortality and complications (Table II). These results supported that the harmonic scalpel is an effective and safe device for IMA harvest.

\section{CONCLUSION}

Harmonic IMA harvesting may minimise the IMA damage, ensure minimal damage to the IMA, obtain satisfactory graft flow and patency rate, and show good clincial outcomes. The harmonic scalpel is an effective and safe device for IMA harvest. Concerning its major drawback of longer harvest time, it is advised to be used in selected and non-emergent patients for CABG.

\section{CONFLICT OF INTEREST:}

Authors declared no conflict of interest.

\section{AUTHOR'S CONTRIBUTION:}

SMY: Substantial contribution to the conception and design of the work; and the acquisition, analysis, and interpretation of data for the work; drafting the work and revising it critically for important intellectual content; final approval of the version to be published; agreement to be accountable for all aspects of the work in ensuring that questions related to the accuracy and integrity of any part of the work are appropriately investigated and resolved.

\section{REFERENCES}

1. Heckel EB. A case of complete exenteration of the orbit for neglected epithelioma of the eyelids by means of electrocautery. Trans Am Ophthalmol Soc 1929; 27:48-51.

2. Hooper RG, Jackson FN. Endobronchial electrocautery. Chest 1985; 87:712-4.

3. Sofer D, Gurevitch J, Shapira I, Paz Y, Matsa M, Kramer A, et al. Sternal wound infections in patients after coronary artery bypass grafting using bilateral skeletonized internal mammary arteries. Ann Surg 1999; 229:585-90.

4. Ohtsuka T, Wolf RK, Hiratzka LF, Wurnig P, Flege JB Jr. Thoracoscopic internal mammary artery harvest for MICABG using the harmonic scalpel. Ann Thorac Surg 1997; 63(6 Suppl):S107-9.

5. Dutta DK, Dutta I. The Harmonic scalpel. J Obstet Gynaecol India 2016; 66:209-10.

6. Balci AY, Alkan P. Harvesting internal mammarian artery by using ultrasound harmonic scalpel: Experience of 154 cases. Anadolu Kardiyol Derg 2010; 10:95-6.
7. Brose S, Fabricius AM, Falk V, Autschbach R, Weidenbach H, Mohr FW. Comparison of ultrasonic scalpel versus argonbeam and conventional electrocautery for internal thoracic artery dissection. Thorac Cardiovasc Surg 2002; 50:71-3.

8. Choo SJ, Lee SK, Chung SW, Kim JW, Sung SC, Kim YD, et al. Does bilateral pedicle internal thoracic artery harvest increase the risk of mediastinitis? Yonsei Med J 2009; 50:78-82.

9. Higami T, Kozawa S, Asada T, Shida T, Ogawa K. Skeletonization and harvest of the internal thoracic artery with an ultrasonic scalpel. Ann Thorac Surg 2000; 70:307-8.

10. Kieser TM, Rose MS, Aluthman U, Narine K. Quicker yet safe: Skeletonization of 1640 internal mammary arteries with harmonic technology in 965 patients. Eur J Cardiothorac Surg 2014; 45:e142-50.

11. Lamm P, Juchem G, Weyrich P, Schütz A, Reichart B. The harmonic scalpel: Optimizing the quality of mammary artery bypass grafts. Ann Thorac Surg 2000; 69:1833-5.

12. Orejola WC, Villacin AB, Defilippi VJ, Mekhjian HA. Internal mammary artery harvesting using the harmonic scalpel. ASAIO J 2000; 46:99-102.

13. Pektok E, Cikirikcioglu M, Engin C, Daglioz G, Ozcan Z, Posacioglu $H$. Does harvesting of an internal thoracic artery with an ultrasonic scalpel have an effect on sternal perfusion? J Thorac Cardiovasc Surg 2007; 134:442-7.

14. Bakuy V, Unal O, Gursoy M, Kunt A, Ozisik K, Sargon M, et al. Electron microscopic evaluation of internal thoracic artery endothelial morphology in diabetic coronary bypass patients. Ann Thorac Surg 2014; 97:851-7.

15. Lehtola A, Verkkala K, Järvinen A. Is electrocautery safe for internal mammary artery (IMA) mobilization? A study using scanning electron microscopy (SEM). Thorac Cardiovasc Surg 1989; 37:55-7.

16. Bulat C, Pešutić-Pisac V, Capkun V, Marović Z, Pogorelić Z, Družijanić N. Comparison of thermal damage of the internal thoracic artery using ultra high radiofrequency and monopolar diathermy. Surgeon 2014; 12:249-55.

17. Boyd WD, Kiaii B, Novick RJ, Rayman R, Ganapathy S, Dobkowski WB, et al. RAVECAB: improving outcome in offpump minimal access surgery with robotic assistance and video enhancement. Can J Surg 2001; 44:45-50.

18. Kiaii B, McClure RS, Stitt L, Rayman R, Dobkowski WB, Jablonsky G, et al. Prospective angiographic comparison of direct, endoscopic, and telesurgical approaches to harvesting the internal thoracic artery. Ann Thorac Surg 2006; 82:624-8.

19. Kieser T, Rose MS, Aluthman U, Narine K. Quicker and safer: Skeletonization of internal mammary arteries with harmonic technology in 910 patients with 1533 mammary arteries. Interact Cardiovasc Thorac Surg 2013; 17(suppl 2):S114-5. 